\title{
Studies on Anti-Leprotic Agents : On 4-Dimethylaminobenżaldehyde-4'-oxyphenyl- thiosemicarbazone (DOT) and It's Drivatives
}

\author{
Yoshitsugu SATAKE \\ National Leprosarium Kikuchi-Kefuen (Director. Dr. K. Shiga)
}

Since the discovery of anti-leprotic agents such as Sulfone, long acting Sulfamine, Antibiotics and Thiourea etc., other new drugs have been studied in respect to their anti-leprotic activity.

The thiourea family drugs have been applied in leprosy by many authors, all reporting good results. The chemical structural formula of thiourea and thiosemicarbazide are exactly like each other. There-fore, the author has expected good effect to treatment of leprosy by thiosemicarbazide drugs. On this idea, the author has synthesed new some of compounds as follow.

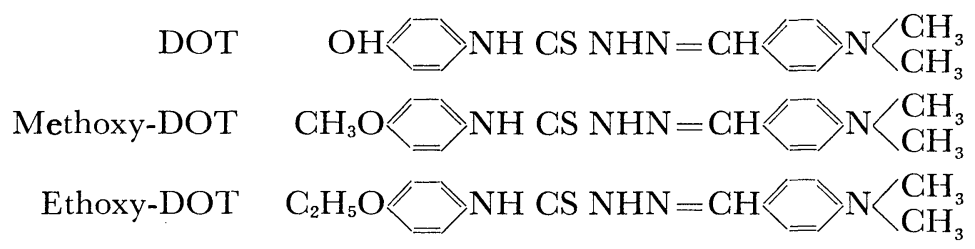

These compounds have proved antibacterial action $\left(\mathrm{H}_{37} \mathrm{RV}\right)$ in $70,000 \quad 100,000$ times diluted solutions, and these toxicity was very little in experiment.

Accordingly, the author believes these compounds can be used to application for clinic of leprosy or tuberculosis. 


\title{
治瀨薬の研究：4-Dimethylaminobenzaldehyde -4 - oxyphenyl-thiosemicarbazone（DOT）並びにその 誘導体について
}

\author{
佐 竹 義 継 \\ 国立療萑所菊池恵楓園 \\ （園長 志賀一親博士） \\ （受付1965年11月11日）
}

A. 前 言

sulfone 1) 剂が癩に有効である事は周知の通りであ る。次に thiourea ${ }^{2}$ 系薬物が登場しその效果は認められ た。著者は前者と構造在近似する thiosemicarbazide 系 化合物中にも有効な治癩剂があるだろうことは予想しそ の研劣に着手した ${ }^{3)}$ 。A.M. Alonso もとの系列のT B 1 について治癩効果を発表している。よって著者は化学 構造が Cida 1906 に類似した thiosemicarbazone 化合 物即ち 4-Dimethylaminobenzaldehyde-4' - oxyphenylthiosemicarbazone（DOTと仮称）及びその-OH壆の Hを alkyl 基で置换した methoxy, ethoxy, の誘導体 を新たに合成した。（Fig 1）しかもその中 DOTは優 秀な抗菌作用 (M. tuberculosis AOYAMAに対して) を
示し，他の二者もこれにはやや劣るが备々抗菌力を有す る事を知った。

よってこれ等を臨床に応用する前提として基礎実験を 行なったのでとてに発表する。

\section{B. 実 験 の 部}

1. 合 成

次のような行程によって合成を行なった。（Fig2）先 づ p-aminophenol (または methoxy 或は ethoxyaniline)を二流化炭素之煮沸し析出する 4-4' -dioxydiphenylthiourea（または 4, $4^{\prime}$-dimethoxy，或は 4, $4^{\prime}$-dietho xyphenylthiourea）を沪取しこれを hydrazinhydrate で 分解して p-oxyphenylthiosemicarbazide（または pmethoxy 或いは p-ethoxyphenylthiosemicarbazide) 得

Fig. 1 The structural formula of compounds

DOT
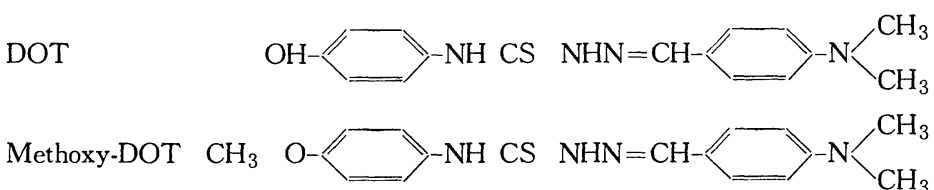

Ethoxy-DOT

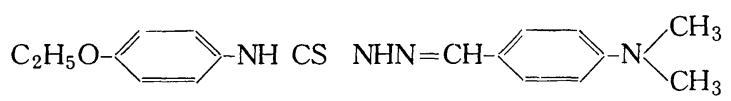

Fig. 2 Process of synthesis of alkylozy-DOT

$$
\left(\mathrm{R}=\mathrm{CH}_{3}, \mathrm{C}_{2} \mathrm{H}_{5}\right)
$$

$\mathrm{CS}_{2}$

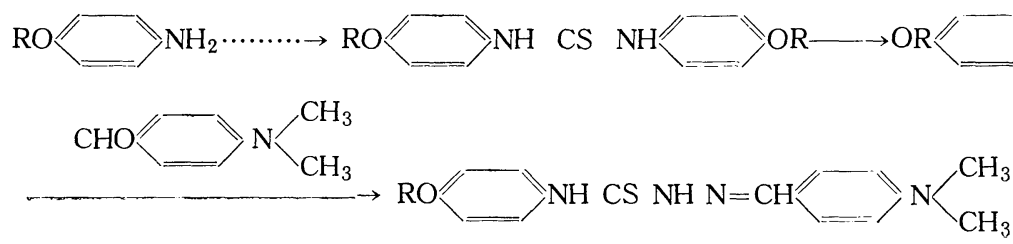


る。これと dimethylaminobenzaldehyde とを無水 Et$\mathrm{OH}$ で絎合させて DOT（または methoxy-DOT，およ びethoxy-DOT) を得た。

4, 4'-dioxy-diphenyl-thiourea の合成

Kalckhoff5) および Hugershoff6) の方法によって合 成した, p-aminophenol 22.0g. Et-OH $250 \mathrm{ml} \mathrm{CS} 27.6$ g. 少量の $\mathrm{S}$, 以上混合水浴上飞 $2 \mathrm{hrs}$. 加温沸騰, 冷後 析沁した鱗片状絬晶を熱湯から再結晶した。収量 $10 \mathrm{~g}$, m. p. $220^{\circ} \sim 225^{\circ} \mathrm{C} \mathrm{C}_{13} \mathrm{H}_{12} \mathrm{O}_{2} \mathrm{~N}_{2} \mathrm{~S}$ 元䒺分析 Calcd, C

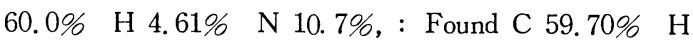

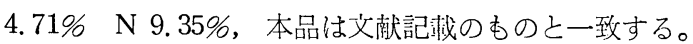

\section{4, 4'dimethoxy-diphenyl-thiourea の合成}

H. Salkowski ${ }^{7)}$ の方法に準拠して合成した。p-anisidin $24.8 \mathrm{~g}, \mathrm{Et}-\mathrm{OH} 150 \mathrm{ml}, \quad \mathrm{CS}_{2} 7.6 \mathrm{~g}, \mathrm{~S}$ 少量を加えて 2 hrs. 加温然沜した。冷後釗状絬唱析出, Et-OH から再 結品，m. p. $191^{\circ} \sim 192^{\circ} \mathrm{C}$ 収量 $12 \mathrm{~g}, \mathrm{C}_{15} \mathrm{H}_{16} \mathrm{O}_{2} \mathrm{~S}$ 元絜分 析Calcd, C 63.34\% H 5.63\% N 8.54\% H 6.01\% N 8.25\% よって文献記载物と一致する。

\section{4, 4'-diethoxy-diphenyl-thiourea の合成}

Hugershoff 6) の方法によって合成した。即ち pphenetidin $50 \mathrm{~g}$ に $\mathrm{CS}_{2} 20 \mathrm{~g}$, Et-OH $300 \mathrm{ml}$., S $7 \mathrm{~g}$. を 混合し水浴上 $2 \mathrm{hrs}$. 還流黄沸した。析出した鱗片状絬晶 を熱晹から再絬鼠した。収量 $40 \mathrm{~g}, \mathrm{~m} . \mathrm{p}, 168^{\circ} \sim 170^{\circ} \mathrm{C}$, $\mathrm{C}_{17} \mathrm{H}_{20} \mathrm{O}_{2} \mathrm{~N}_{2} \mathrm{~S}$, 分元素分析 Calcd C $64.5 \%$ H 6.3\%
N 8.8\%, Found C 64.82\% H 6.43\% N 8.95\%, よって文献記載物に一致する。

4-oxy-phenyl-thiosemicarbazide の合成

4, 4'-dioxy-phenyl-thiourea $20 \mathrm{~g}$ に50\% hydrazine hydrate $10 \mathrm{~g}, \mathrm{Et}-\mathrm{OH} 300 \mathrm{ml}$ を加えて $4 \mathrm{hrs}$. 水浴上に 遝流堂沸すれば最初黄色から緑色となり再び淡黄色の溶 液となる。約半量になるまで $\mathrm{Et}-\mathrm{OH}$ を溜去し放冷すれ ば結晶析出する。 $\mathrm{Et}-\mathrm{OH}$ から再結䙹, $\mathrm{mp} 168^{\circ} \sim 170^{\circ} \mathrm{C}$ 収量 $12 \mathrm{~g} \mathrm{C}_{7} \mathrm{H}_{9} \mathrm{ON}_{3} \mathrm{~S}$, 元素分析 Calcd, C $45.9 \%, \mathrm{H}$ $4.92 \% \mathrm{~N} \mathrm{23.0 \%}$ : Found C 45.28\% H $4.80 \% \mathrm{~N}$ $23.90 \%$

4-methoxy-phenyl-thiosemicarbazide の合成

本化合物の合成として既に Busch, Ulmer ${ }^{8)}$ 等の報 告があるが著者は 4, $4^{\prime}$-dimethoxy-diphenyl-thiourea よ り出発した。即ち本品を $10 \mathrm{~g}$. とりてれに $50 \% \mathrm{NH}_{2} \mathrm{NH}_{2}$ 5g. Et-OH $150 \mathrm{ml}$ を加えて $4 \mathrm{hrs}$. 水浴上に還流黄沸して 冷後析出する板状淡紅色の結晶を濾取し Et-OH から再 結晶した。収量 $3 \mathrm{~g} ., \mathrm{mp} 145 \sim 146^{\circ} \mathrm{C}, \mathrm{C}_{8} \mathrm{H}_{11} \mathrm{ON}_{3} \mathrm{~S}$, 元素分析 Calcd. C 48. 73\%, H 5.58\%, N 21.31 $\%$, : Found C 49.21\%, H 5.32\%, N 20.92\%

4-ethoxy-phenyl-thiosemicarbazide の合成

本合成は前述同㥞 4, $4^{\prime}$-diethoxy-diphenyl-thiourea よ り出発した。本品 $50 \mathrm{~g}$, 在 $50 \% \mathrm{NH}_{2} \mathrm{NH}_{2} 25 \mathrm{~g}, \mathrm{Et}-\mathrm{OH}$ $500 \mathrm{ml}$, の溶液に加え $4 \mathrm{hrs}$, 還流黄沸した。冷後析出す

1) Elementary analysis thiosemicarbazide derivatives

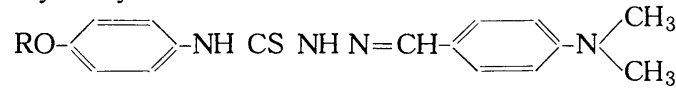

\begin{tabular}{|c|c|c|c|c|c|c|c|c|c|c|}
\hline \multirow{3}{*}{ No. } & \multirow{3}{*}{ Formula } & \multirow{3}{*}{$\begin{array}{l}\text { Molecu- } \\
\text { lar } \\
\text { weight }\end{array}$} & \multirow{3}{*}{$\begin{array}{l}\mathrm{mp} \\
\mathrm{C}^{\circ}\end{array}$} & \multirow{3}{*}{$\begin{array}{l}\text { Appear- } \\
\text { ance }\end{array}$} & \multicolumn{6}{|c|}{ Analysis } \\
\hline & & & & & \multicolumn{3}{|c|}{ Calcd. (\%) } & \multicolumn{3}{|c|}{ Found $(\%)$} \\
\hline & & & & & $\mathrm{C}$ & $\mathrm{H}$ & $\mathrm{N}$ & $\mathrm{C}$ & $\mathrm{H}$ & $\mathrm{N}$ \\
\hline I & $\begin{array}{c}\mathrm{R}=\mathrm{H} \\
\mathrm{C}_{16} \mathrm{H}_{18} \mathrm{ON}_{4} \mathrm{~S}\end{array}$ & 314 & 215 & $\begin{array}{l}\text { yellow } \\
\text { needles }\end{array}$ & 61.14 & 5. 75 & 17.83 & 60.86 & 6. 01 & 18.01 \\
\hline II & $\begin{array}{c}\mathrm{R}=\mathrm{CH}_{3} \\
\mathrm{C}_{17} \mathrm{H}_{20} \mathrm{ON}_{4} \mathrm{~S}\end{array}$ & 328 & $207 \sim 209$ & $\begin{array}{l}\text { yellow } \\
\text { powder }\end{array}$ & 62.19 & 6.09 & 17.09 & 63.07 & 6.16 & 16.92 \\
\hline III & $\begin{array}{c}\mathrm{R}=\mathrm{C}_{2} \mathrm{H}_{5} \\
\mathrm{C}_{18} \mathrm{H}_{22} \mathrm{ON}_{4} \mathrm{~S}\end{array}$ & 342 & $198 \sim 202$ & $\begin{array}{l}\text { yellow } \\
\text { powder }\end{array}$ & 63.2 & 6.4 & 16.3 & 64.86 & 7.13 & 29.16 \\
\hline
\end{tabular}


る白色結晶を濾取し更に滤湤を減王濃縮してその結晶を 集めた。Et-OH加ら再結晶, 収量 $20 \mathrm{~g}$. mp. $145 \sim 147^{\circ} \mathrm{C}$, $\mathrm{C}_{9} \mathrm{H}_{13} \mathrm{ON}_{3} \mathrm{~S}$, 元素分析 Calcd. C $51.1 \%, \mathrm{H} 6.2 \%$, N $19.9 \%$ : Found C 52.34\%, H 6.39\%, N $19.16 \%$

4-dimethylamino-benzaldehyde-4'-oxy phenylthiosemicarbazone の合成

4-oxyphenyl-thiosemicarbazide $2.5 \mathrm{~g}$ を先づ無水Et-OH
$100 \mathrm{ml}$. 亿溶解し次に 4-dimethylamino-benzaldehyde 2.1 g. を加えて水浴上に䢱流意沸 2 hrs. 最初黄色の液となり 次に黄色針状の結晶析出与る。冷後滤別して熱 $\mathrm{Et}-\mathrm{OH}$ より再結昆する。 $\mathrm{mp} .215^{\circ} \mathrm{C}$ 収量3. $0 \mathrm{~g} ., \mathrm{C}_{16} \mathrm{H}_{18} \mathrm{ON}_{4} \mathrm{~S}$ 元素分析 Calcd C 61.14\%, H 5.75\%, N 17.83\%, : Found. C 60.86\%, H 6.01\%, N 18.01\%, 4-dimethylamino-benzaldehyde-4'-methoxyphenyl-thiosemicarbazone の合成

2) Infrared absorption spectra

DOT (1 mg./500 mg. KBr)
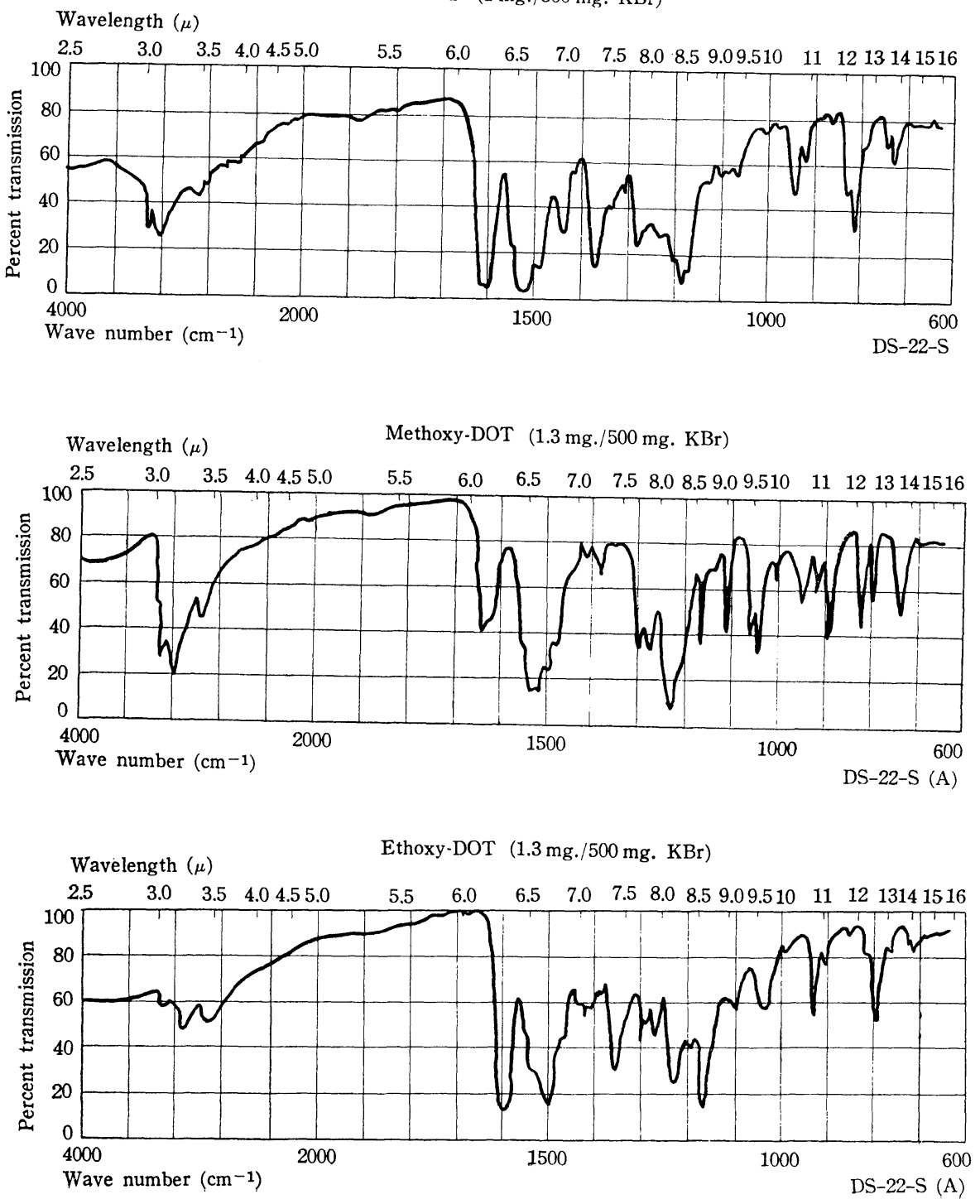
4-methoxy-phenyl-thiosemicarbazide 2.5g. を無水 Et-

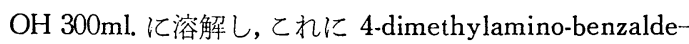
hydel $1.8 \mathrm{~g}$. を加え水浴上に還流募沸 $2 \mathrm{hrs}$. 冷後析出し た結晶を滤取し Et-OH から再結晶, 収量 $2.3 \mathrm{~g}$. 淡黄色 粉状結晶, $\mathrm{mp} .207 \sim 209^{\circ} \mathrm{C}, \mathrm{C}_{17} \mathrm{H}_{20} \mathrm{ON}_{4} \mathrm{~S}$, 元菜分析 Calcd. C 62.19\%, H 6.09\%, N 17.07\% : Found. C $63.07 \%$, H $6.16 \%, \mathrm{~N} 16.92 \%$

4-dimethylamino-benzaldehyde-4'-ethoxyphenylthiosemicarbazone の合成

4-ethoxyphenyl-thiosemicarbazide 15g. を無水 Et-OH $300 \mathrm{ml}$. に溶解し, これに 4-dimethylamino-benzaldehyde 10. $5 \mathrm{~g}$. を加え水浴上で還流薏沸 $2 \mathrm{hrs}$. 最初澄明に溶解し 時開の経過とと屯に黄褐の液となる，そして更に黄色結 鼠が析出する。冷後滤別 Et-OH の多量から再絬昆, mp. 198 202 ${ }^{\circ} \mathrm{C}$ 黄色粉状結晶収量 $2.8 \mathrm{~g} . \mathrm{C}_{18} \mathrm{H}_{22} \mathrm{ON}_{4} \mathrm{~S}$, 元装分析 Calcd. C 63.2\%, H 6.4\%, N 16.3\% : Found C 64.86\%, H 7.13\%, N 16.92\%

DOTおよび Methoxy-DOT, Ethoxy-DOT の 元素分析並びに赤外線吸収スペクトルについて 図表 1)，2）を参照

2. 瑇性と抗菌作用

a ）毒性について

$20 \mathrm{~g}$. 前後のマウス今の腹腔内にこれら化合物の生理食 塩水眯水物を注射し 5 日閒に於けるマウスの獘死を众讨 した。

平均致死量は次の通りである。
DOT
$4300 \mathrm{mg} / \mathrm{kg} \pm$

$\begin{array}{ll}\text { Methoxy-DOT } & 6850 \mathrm{mg} / \mathrm{kg} \pm \\ \text { Ethoxy-DOT } & 5250 \mathrm{mg} / \mathrm{kg} \pm\end{array}$

以上の結果毒性はかなり弱かった。

\section{b ) 抗菌作用について}

i ）使用菌 $\cdots \mathrm{H}_{37} \mathrm{RV}$ 青山株

ii）培地…変法 Kichner 合成培地に人血浆を $10 \%$ に加 えたものを使用した。

処方

$$
\begin{array}{lr}
\text { グリセリン } & 20 \mathrm{ml} \\
\text { グルタミン酸ソーダ } & 10.0 \mathrm{~g} . \\
\text { クエン酸ソーダ } & 2.5 \mathrm{~g} . \\
\text { 硫酸マグネシウム } & 0.6 \mathrm{~g} . \\
\mathrm{Na}_{2} \mathrm{HPO}_{4} \cdot 12 \mathrm{H}_{2} \mathrm{O} & 3.0 \mathrm{~g} . \\
\mathrm{K}_{2} \mathrm{HPO}_{4} & 4.0 \mathrm{~g} .
\end{array}
$$

以上を精製水 $100 \mathrm{ml}$ に溶解し， $10 \% \mathrm{NaOH}$ でPH6. 8 に なるよう調整した。次に $120^{\circ} \mathrm{Cで} 20 \mathrm{~min}$. 滅菌してれに人 血浆を10\%になるよう加えた。

iii) 試料……DOT, Methoxy-DOT, Ethoxy-DOT, の 备々を少量の ethylenglycol に温時溶解し，ての液を一 定量採取し所定の濃度になるよう培地に加えた。

iv）実施方法……上記の培地 $4.5 \mathrm{ml}$ を隇菌試験管に入れ 一定濃度になるように培地にこの溶液を加えてその試料 の濃度が 1 万倍から10万倍になるように各試験管を準備 した。これに上記菌浮游液を $0.1 \mathrm{ml}$ 宛加えて $37^{\circ} \mathrm{C}$ に 17 日 間培挙し，その菌の発育程度を観察した。

以上の結果 DOT が最も抗菌作用 $\left(\mathrm{H}_{37} \mathrm{RV}\right.$, 青山株 に対して）が強く Ethoxy-DOT，がこれに次ぎ，

\begin{tabular}{|c|c|c|c|c|c|c|c|c|c|c|c|c|}
\hline \multicolumn{2}{|r|}{ No. } & 1 & 2 & 3 & 4 & 5 & 6 & 7 & 8 & 9 & 10 & 11 \\
\hline \multicolumn{2}{|c|}{ dose mg. $/ \mathrm{kg}$. } & 3000 & 3500 & 4000 & 4500 & 5000 & 5500 & 6000 & 6500 & 7000 & 7500 & 8000 \\
\hline \multirow{3}{*}{ 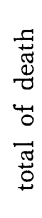 } & DOT & $0 / 10$ & $2 / 10$ & $4 / 10$ & $8 / 10$ & $7 / 10$ & $10 / 10$ & $10 / 10$ & $10 / 10$ & $10 / 10$ & $10 / 10$ & $10 / 10$ \\
\hline & Methoxy-DOT & $0 / 10$ & $0 / 10$ & $0 / 10$ & $0 / 10$ & $0 / 10$ & $0 / 10$ & $1 / 10$ & $3 / 10$ & $6 / 10$ & $8 / 10$ & $10 / 10$ \\
\hline & Ethoxy-DOT & $0 / 10$ & $0 / 10$ & $1 / 10$ & $2 / 10$ & $4 / 10$ & $6 / 10$ & $7 / 10$ & $10 / 10$ & $10 / 10$ & $10 / 10$ & $10 / 10$ \\
\hline
\end{tabular}

Methoxy-DOT が最も弱いがしかし何れも優れた抗菌 を有することが判明した。

Toxicity of DOT, Methoxy-DOT and Ethoxy-DOT

(administered intra-abdomineously)

Mice 20g. \pm 
Antibacterial action to M. tuberculosis

$\mathrm{H}_{37} \mathrm{RV}$ (Aoyama), 27 days

\begin{tabular}{|c|c|c|c|c|c|c|c|c|c|c|}
\hline Compunds & $\underset{\times}{10.000}$ & $\underset{\times}{20.000}$ & $\underset{\times}{30.000}$ & $\underset{\times}{40.000}$ & $\underset{\times}{50.000}$ & $\begin{array}{c}60.000 \\
\times\end{array}$ & $\begin{array}{c}70.000 \\
\times\end{array}$ & $\begin{array}{c}80.000 \\
\times\end{array}$ & $\underset{\times}{90.000}$ & $\underset{\times}{100.000}$ \\
\hline DOT & - & - & - & - & - & - & - & - & - & \pm \\
\hline Methoxy-DOT & - & - & - & - & - & - & - & + & H & H \\
\hline Ethoxy-DOT & - & - & - & - & - & - & + & + & H & m \\
\hline Contrast & H & H & H & H & H & HI & Ht & H & Ht & m \\
\hline
\end{tabular}

\section{c) 結言}

本研究に於て次の事項を明らかにすることを得た。

1) DOT, Methoxy-DOT, Ethoxy-DOT の合成法を 確立した。

2 ) 以上 3 化合物の各々は素性が低く医薬品として使用 可能と䍐考される。

3 ）との 3 化合物の各々は優れた抗菌作用を結核菌 $\mathrm{H}_{37}$

RV に於て示した。

以上の結果からDOT, Methoxy-DOT, Ethoxy-DOT

は「らい」抢よび結核症の臨床に応用し得る可能性があ るものと䍐考される。

本研究に多大な激励之援助を赐わった当園辰志賀一親 博士，並びに医務部長中村啓八部博士，执よび熊本大学 赤塚政美博士，化血研清崎俊之㮐長敒意を表する。
参考文 献

1) Faget, et al : Public Health Report, 58, 1709 (1943)

2) Davey, T. F. and Currie, G. : Leprosy Review, 27, 94. (1956)

3 ) 佐竹: 九州薬学会々摯17, 10 (1961) 佐竹 : レプ 亏第34卷第 1 号 (1965)

4 ) A. M. Alonso : VII International Cong. of Leprology. (1958)

5) Kalckhoff : Berichte der Deut. Chem. G. 16, (1830)

6) Hugershoff : Ber. Deut. Chem. G. 32, 2246

7) H. Salkowski : Ber. Deut. Chem. G. 7, 1012

8 ) Busch, Ulmer : Ber. Deut. Chem. G. 35, 1714 